\title{
Past experiences, current realities and future possibilities for HIV nursing education and care in Canada
}

\author{
J udy Mill ${ }^{1}$, Vera Caine ${ }^{1}$, Cheryl Arneson ${ }^{2}$, Geoffrey Maina ${ }^{1}$, Anthony De Padua ${ }^{3}$, Margaret \\ Dykeman $^{4}$
}

1. Faculty of Nursing, University of Alberta, Edmonton, Alberta, Canada. 2. The Hospital for Sick Children, Toronto, Ontario, Canada. 3. Department of Indigenous Education, Health and Social Work, First Nations University, Prince Albert, Saskatchewan, Canada. 4. Faculty of Nursing, University of New Brunswick, Fredericton, New Brunswick, Canada.

Correspondence: Judy Mill. Address: Faculty of Nursing, University of Alberta, $3^{\text {rd }}$ floor, Edmonton Clinic Health Academy, 11405 -87 Ave, Edmonton, AB T6G 1C9, Canada. Email: judy.mill@ualberta.ca

Received: January 14, 2014

Accepted: March 10, 2014

Online Published: April 7, 2014

DOI : $10.5430 /$ jnep.v4n5p183

URL: http://dx.doi.org/10.5430/jnep.v4n5p183

\begin{abstract}
Nurses may have inadequate basic education and opportunities for continuing education in relation to HIV care. As well nurses may perpetuate and impose stigma. We developed, implemented and evaluated an educational intervention to reduce stigma and discrimination among nurses providing HIV care. The intervention used a mentorship model that brought experienced nurses in HIV care and people living with HIV together with nurses who wanted to learn more about HIV nursing care. We examined our findings in relation to past experiences, current realities and future possibilities for HIV nursing education and care in Canada. Our findings demonstrated that many nurses were interested in improving their HIV care, yet few opportunities existed for them to do so. We found that HIV nursing education and expertise were significantly different among participants and across clinical sites. This difference was visible in basic education, services offered for HIV and AIDS care, the collaborative and inter-professional nature of care, and opportunities for continuing education. Mentorship education is an effective strategy to not only address a critical void in knowledge, but also to promote a fundamental shift in attitudes. With the recent call by the World Health Organization to place nurses in key positions to provide HIV care, treatment and prevention, it is imperative to prepare nurses at both the undergraduate and graduate level, as well as those in practice, to fulfill this call.
\end{abstract}

\section{Key words}

HIV, Nursing, Intervention, Stigma, Research

\section{I ntroduction}

Stigma and discrimination has the potential to influence the ability of persons living with HIV (PHAs) to access care, treatment and support ${ }^{[1]}$. AIDS stigma experienced by many individuals often intersects with other forms of stigma related to behavior, culture, gender, sexual orientation or social class ${ }^{[2]}$. Several studies have documented that some health professionals, including nurses, provide discriminatory care for PHAs ${ }^{[2-4]}$. Nurses have a primary responsibility for providing direct patient care to PHAs and therefore it is critical that nurses are knowledgeable about HIV and AIDS and 
provide ethical care. Despite this it has been reported that nurses may have inadequate basic education and opportunities for continuing education in relation to HIV care. The purpose of the current study was to develop, implement and evaluate an educational intervention to reduce stigma and discrimination among nurses providing HIV care. The intervention utilized a mentorship model that brought experienced nurses in HIV care and PHAs together with nurses who wanted to learn more about HIV nursing care. In the current paper we present findings related to nurses' preparation for, and experience with, HIV nursing care. We will examine our findings in relation to the past experiences, current realities and future possibilities for HIV nursing education and care in Canada.

\subsection{Literature review}

\subsubsection{Looking back: Past experiences in the nursing response to HIV in North America}

In 1987 the Association of Nurses in AIDS Care (ANAC) was formed by a group of nurses in the United States to provide support for "...nurses who were overwhelmed with the violence of HIV as well as the hostility of the social reactions to those with the infection...” ${ }^{[5, \text { p. }}{ }^{4}$. Since its inception, ANAC has continued to provide guidance for nurses related to HIV nursing care and education. The mission of ANAC is to "...promote the individual and collective professional development of nurses involved in the delivery of health care to persons infected or affected by HIV and to promote the

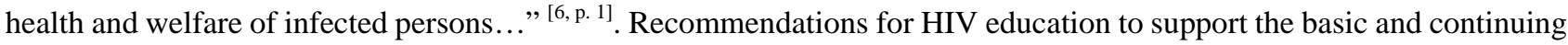
professional development of nurses are integral to ANAC's mission. From early in the epidemic ANAC saw the need for specialty education and developed a Core Curriculum for HIV/AIDS Nursing, which is now in its $3^{\text {rd }}$ edition ${ }^{\text {[7] }}$. This curriculum outlines an educational framework for nurses providing HIV nursing care in general settings and for those preparing to work in HIV specialty settings.

In 1988, shortly after the formation of ANAC, a group of Canadian nurses working in HIV care began to meet in Toronto on a regular basis to provide support and professional development ${ }^{[8]}$. These nurses were inspired by the work of ANAC and applied to become the first ANAC international chapter ${ }^{[8]}$. After a planning and brainstorming meeting at the VI International AIDS Conference in San Francisco in 1991, a group of nurses from across Canada, working in a range of practice settings that provided care for PHAs, met in Ottawa to draft a constitution for the Canadian Association for Nurses in AIDS Care ${ }^{[8]}$. This group of nurses was successful in their application to become a National Nursing Interest Group of the Canadian Nurses’ Association and became the first Canadian professional association in HIV and AIDS ${ }^{[8]}$.

In 2005, at the International Council of Nurses (ICN) Quadrennial Congress, ICN launched an HIV/AIDS Network ${ }^{[9]}$. The presidents of ANAC and CANAC were part of the launch and committed to the ongoing involvement of their organizations in the ICN HIV/AIDS Network. The aim of the network was to promote linkages between nurses and national organizations, to share knowledge and expertise on HIV care and to become a global resource for nurses working in HIV policy, practice, education and research. The HIV/AIDS network produces a newsletter HIV \& AIDS Network Bulletin and meets regularly, the last time in May 2011 in Malta during the ICN conference ${ }^{[9]}$. In addition the HIV/AIDS network has developed a list of essential nursing competencies related to HIV and AIDS that provide guidance related to: care, treatment and prevention of HIV and AIDS; psychological, spiritual, and ethical issues related to HIV and AIDS; psychomotor skills related to HIV and AIDS nursing care; and professional expectations for nurses providing HIV and AIDS nursing care ${ }^{[10]}$. Relf and colleagues ${ }^{[10]}$ suggest that these competencies can be used to redesign nursing curricula and to develop capacity building of nurses already in practice.

\subsubsection{Looking back: HIV education in nursing}

Early in the epidemic, several authors ${ }^{[11-13]}$ commented on the unique challenges and issues related to HIV education for nurses in the United States. This is due in part to the social construction of HIV illness, the need to discuss uncomfortable issues, and the stigma and discrimination surrounding HIV infection ${ }^{[12-14]}$. In 1992, ANAC developed a position paper advocating that nurses incorporate an assessment of HIV risk in all nursing assessments and acquire skills to assist patients to develop a harm reduction plan ${ }^{[15]}$. In 1996, Corless and Nokes ${ }^{[12]}$ evaluated nursing education's response to the AIDS 
pandemic and highlighted the need to provide entry level nursing education that went beyond knowledge acquisition to include an exploration of attitudes, training in risk reduction and the development of caring values. They described integrated and content-specific approaches to incorporating HIV content in nursing curricula; however, they came to the conclusion that neither approach was being systematically incorporated into nursing education in the United States.

The need for HIV and AIDS training and education for Canadian nurses, both undergraduate and post-graduate, was also identified early in the epidemic. In 1996 CANAC developed one in a series of seven modules for the Federal government on topics related to HIV and AIDS to provide continuing professional education for health professionals ${ }^{[16]}$. More recently, in 2000 Paquin and Lambert ${ }^{[17]}$ argued that the provision of HIV and AIDS education for nurses resulted in improved care for PHAs. Finally, a team of health professionals affiliated with the University of British Columbia recently initiated an interdisciplinary course for senior students in the health and human service professions focused on HIV prevention and care ${ }^{[18,19]}$. More than 400 students have completed the course which continues to be offered at this time. More recently in a position paper outlining best practices for caring for persons at risk for or living with HIV ${ }^{[20]}$, CANAC highlighted the need to integrate principles of HIV care into undergraduate nursing curricula.

\subsubsection{Current realities in HIV nursing education}

Although there have been some efforts in Canada to provide basic knowledge about HIV and AIDS early in the epidemic, a recent position paper by the CANAC ${ }^{[21]}$ argues that a large proportion of new nursing graduates do not have the minimum level of knowledge that is required to provide safe and competent care for PHAs. The CANAC position paper calls for the development of core competencies for HIV nursing undergraduate education. CANAC recommends that, at a minimum, all undergraduate nursing students participate in educational sessions to ensure that they understand their professional responsibilities in relation to the confidentiality and dignity of PHAs ${ }^{[21]}$. They argue that undergraduate curriculums should include a minimum of 6 to 12 hours of content about HIV transmission, testing, treatment, counselling and care from both a biomedical and psychosocial perspective. In addition CANAC advocates the development of additional elective courses and where feasible, clinical practica to provide experience caring for PHAs.

\subsubsection{Mentorship in HIV nursing education}

Mentorship has been used for several decades as an educational approach in nursing for both undergraduate and post-graduate teaching ${ }^{[22]}$. Examples of multiple mentoring approaches, with more than one mentor and mentee in a team, have been described in health professions including nursing ${ }^{[23]}$ and occupational therapy ${ }^{[24]}$. Callaghan and colleagues ${ }^{[23]}$ compared the strengths and limitations for nursing students working with one mentor in the preceptorship model versus with multiple mentors in collaborative learning units. Although the authors reported that each approach provided complimentary learning opportunities, having multiple mentors enabled students to experience different approaches to care, appreciate the importance of a multidisciplinary team in providing complex care, and begin to work independently. Ambrose ${ }^{[25]}$ suggests that the benefits of multiple mentoring include the ability to "capitalize on the unique skills of many individuals...; support team building and mutual competency development...; and take advantage of the seasoned expertise of one knowledgeable individual...” (p. 58) and make it available to multiple learners.

Although the role of mentors in clinical learning has been described, the concept of mentorship in HIV education has not been well documented ${ }^{[26]}$. In 1996, Gallagher ${ }^{[13]}$ recommended that the inclusion of PHAs “....as active participants in an HIV educational process [in the United States] helps learners to question and re-shape attitudes...” (p. 10). Based on findings from a small qualitative study with American nurse mentees and mentors that did not incorporate PHAs, Grindel and Patsdaughter ${ }^{[26]}$ recommended mentorship as a key strategy for HIV professional development and highlighted the need for research to examine the effectiveness of nurse mentorship programs. In Canadian HIV nursing education there are very few examples of the use of a mentorship model and we were unable to find any examples of the inclusion of PHA mentors. In 1997, CANAC collaborated with several provincial and national organizations to initiate a mentorship program for Quebec nurses providing care to PHAs ${ }^{[16]}$. In this program, nurses who were expert in AIDS care were partnered with nurses who were novice in AIDS care to create a network of nurse mentors in Quebec; however, PHAs did 
not have a mentoring role. More recently, Solomon, O’Brien, Hard, Worthington \& Zack ${ }^{[27]}$ evaluated a pilot HIV mentorship program for rehabilitation professionals. The program was unique due to the incorporation of problem-based learning, interprofessionalism, multiple mentoring opportunities and the inclusion of PHAs as mentors.

\subsubsection{Background}

In 2010 we received funding from the Canadian Institutes for Health Research to engage in a national study entitled $A$ Clinical Mentorship Model for Canadian Nurses in HIV Care. Our study was conceptualised in collaboration with the Canadian Association of Nurses in AIDS Care (CANAC), the Canadian Working Group on HIV and Rehabilitation (CWGHR), the Canadian AIDS Treatment and Information Exchange (CATIE) and several AIDS Service Organizations (ASOs). A transformative learning model ${ }^{[28]}$ provided a conceptual framework for the study. In this paper, we present qualitative findings related to: nurses' knowledge about HIV care at the outset of the intervention; nurses' educational opportunities related to HIV and AIDS; and participants' motivation to participate in the project. Findings related to the experiences of the PHAs who participated in the mentorship program, the process of implementing the intervention, and the quantitative survey data will be reported elsewhere.

\section{Methods}

A mixed method exploratory evaluation design was used to explore the research questions; interviews, surveys, and field notes were the primary data collection methods. A community-based research approach was used to guide the design, implementation and dissemination of the findings in order to enhance capacity building opportunities. Our study design utilized a multiple mentoring approach ${ }^{[25]}$ that involved PHAs and nurses experienced in HIV care mentoring nurses wanting to learn more about HIV care over a 12 month period. Ethical approval for the study was obtained from the Health Research Ethics Board (Panel B) at the University of Alberta, at each co-investigator affiliated institution, and as required from the partner ASOs, community organizations, and participating clinical agencies at each site. A total of 16 approvals were obtained, however at one site we were unable to obtain approval to go through the ethics review process, while at a second site we were unable to obtain the necessary administrative approval to implement the study. Further details about the implementation process will be reported elsewhere. Written informed consent was obtained from all participants. Mentors and mentees were provided with an honorarium to partially compensate them for their time to attend the three two day workshops during the mentorship intervention. Through the Faculty of Extension at the University of Alberta continuing education credits were provided to nurses and PHAs who completed the twelve-month intervention (a minimum of 100 hours).

The study was implemented at four sites across Canada, two cities and two smaller rural communities (population less than $<75,000)$. Although the study design proposed three two day workshops over twelve months, we were unable to implement the three workshops at all sites. At three study sites we completed three face-to-face workshops (over 12 months), and at one study site two workshops (over six months).

The purpose of the first workshop was to provide an opportunity for participants at each site to form relationships, to meet some members of the research team and to begin the process of knowledge development in relation to HIV care. In addition, during the first workshop we completed an assessment (survey and interview) of learning needs and immediately after the final workshop we assessed learning outcomes. Between the face-to-face workshops, participants met on a monthly basis for two to three hours to continue their learning based on the needs and suggestions of the mentors and mentees. For example, participants were engaged in educational sessions with pharmacists, physicians, social workers, and PHAs and worked on case studies facilitated by the nurse and PHA mentor. One of the co-principal investigators and a research assistant participated in each of the workshops and a project coordinator was responsible for coordinating the workshops, assisting with data collection and overall project management. A community advisory committee advised the research team on the implementation process, the refinement of the mentorship model, and the dissemination of the study findings. 


\subsection{Qualitative data analysis}

NVivo 9 qualitative data analysis software ${ }^{[29]}$ was used to assist with the organization and retrieval of the data. Morse's taxonomy ${ }^{[30]}$, including comprehending, synthesizing, theorizing and re-contextualizing the data, was used to guide the inductive analysis process. A coding framework was developed by the co-principal investigators, a graduate research assistant and the project coordinator using a small subset of the interviews to comprehend the data. As new insights about the data and relationships among the themes were gained during the analysis, the coding framework was refined. During face to face meetings with the core analysis team, synthesis and theorizing of the findings were discussed and completed. The data was re-contextualized utilizing existing literature during the final stage of analysis and writing.

\subsection{Sampling}

Convenience and network sampling were used to recruit participants. Nurse mentors and mentees were recruited via contacts with CANAC members and local co-investigators or in response to a poster in the health facility where they worked. The PHA mentors were recruited with the assistance of the collaborating ASOs. At some sites nurses struggled to obtain permission to participate in the mentorship project resulting in the need to apply for vacation time in order to join the study. Eligibility criteria for all participants included: speaks English; lives within $50 \mathrm{~km}$ of one of the study sites; and willing to participate for the duration of the mentorship program (the estimated time commitment over one year was 2 hours/week for workshops, meetings and interviews). Nurse mentors needed to have several years of experience in HIV prevention and/or AIDS care and PHA mentors needed to be living with HIV or AIDS for at least one year. In addition the nurse mentees and mentors were required to be registered in a provincial jurisdiction.

\section{Findings}

A total of 48 nurses and eight PHAs participated in the mentorship program across the four sites. Seven of the eight nurse mentors had more than ten years of experience, and the majority had a bachelor's degree and worked in a hospital HIV clinic. Four male and four female PHA mentors participated, with most being between 40 and 49 years of age and having known of their diagnosis for more than 11 years. Most (17) of the 40 nurse mentees (38 female, 2 male) worked in public health, with nurse mentees also coming from emergency, specialized community health, mental health, renal, intensive care, acute care, First Nations on-reserve clinics, and long-term care settings. Registered nurse mentees had either a diploma or a bachelor's degree, and many had more than 10 years of experience. One licensed practical nurse participated in the study.

As we began to implement our research project, we noticed that HIV nursing care was approached differently across our four sites. These differences seemed to be related to: the type of site (e.g., urban community versus smaller rural community); the approach to care (e.g., integrated versus HIV-specialized): the current involvement of PHAs in care (e.g., PHAs not usually integrated into care versus integrated as peer navigators); previous opportunities for nurses to learn about HIV nursing care (e.g., more in urban communities versus fewer in smaller, rural communities); political emphasis on, and commitment to, the issue of HIV and AIDS; the evolution of the epidemic (some nurse mentees had extensive experience in HIV nursing care versus others with less experience) and level of stigma and discrimination in the community. The findings presented in this paper are based on data from the qualitative interviews conducted following the first workshop at the four sites completing the intervention, which focused on: nurses' reasons for participating in the mentorship project; nurses’ undergraduate education about HIV; and nurses’ knowledge about HIV.

\subsection{Reasons for participating in the mentorship project}

Most of the nurse mentees spoke about their gaps in knowledge or feelings of inadequacy in caring for a PHA as a motivator to participate in the mentorship project. They were unsure of the best approach to tell a patient that he or she had a positive HIV diagnosis, counsel a new mother who was HIV positive, support an HIV positive client, or integrate a harm reduction approach to care. Many of the nurse mentees felt that they did not have the knowledge needed to provide 
appropriate patient care and hoped that participation in the mentorship project would help to fill this knowledge gap. For some the motivation to learn more was also driven by personal experiences.

The very first time that I tested this individual for HIV, and I did the pre-counselling, and they had been in contact with HIV...Certainly, when that person came back positive and I had to give that news...I felt completely unprepared. (Urban mentee)

[I] had a personal experience with a friend of mine who diagnosed late, already showing signs of AIDS. So kind of stumbled in the middle of being an advocate for him, but not really knowing enough to know what I didn't know, and was I being any help at all, because the area of HIV was not my area of specialty, and I believe that it is a specialty because it's just so distinct in terms of - to hear [nurse mentor 1] talk, you know there's a lot to know. So it's a personal drive for me to just expand my knowledge base, to be a better clinician, so when I have patients who have certain needs, questions, I know what's out there. I may not have the answer, but I can tell you where somebody works that will be able to support you in that. (Rural mentee)

...I don't know enough, and I'm always seeking opportunities to educate myself more and to really build on my experiences and my knowledge base... I want to see how different professionals in the community, what their different roles are, how they play into this community of people living with HIV and people working with HIV. I want to understand a lot of the socioeconomic issues that you're not aware of. I've grown up in a pretty sheltered life, so I don't really know a lot of these things, and I want to know more so, that way I can be more aware of any self-biases, or I'd be more aware of how I can cater my nursing care so that it's culturally sensitive to the people that I work with. (Urban mentee)

One of the nurse mentees recalled a very disturbing experience when she and her emergency room colleagues missed some significant signs and symptoms of HIV in one of their patients:

I had a patient that just sort of stands out in my mind that I think, as emergency care providers, we failed this patient, a gentleman who came back several times for recurring pneumonia over a 6-week period, and was never HIV-tested despite some red flags that perhaps we should have picked up on in retrospect when he came in in respiratory distress and needed to be intubated. Subsequently, he had been tested the visit before and was not given his status until he was just about to be intubated. So that was just a colossal failure, I feel like, on our part, and what could we have done different, what did we miss, and how can we share that knowledge. (Rural mentee)

A few of the nurses believed that stigma and discrimination made it particularly compelling to learn more about HIV and AIDS or to participate as a mentor:

And also, the dimension of stigma is very important to me, and I knew that was involved in this project. I also feel like it was a rare opportunity; I haven't heard about other things like this, so that caught my interest. There aren't a lot of other opportunities to mentor nurses in HIV. (Urban mentor)

But it breaks my heart, being treated so badly [HIV positive patients] when there's no reason for it. I see a lot of stigma against the addiction stuff, and I don't even know what to do. So I'm kind of hoping, through this project, that I come out with more information for the people that I work with, and try and help them understand that this is—you know, everything — addiction, HIV, Hepatitis—it's a disease, and you can't treat people poorly because you've got preconceived ideas about where it came from. (Rural mentee)

One of the nurse mentees shared a very troubling incident she observed as a student which motivated her to join the mentorship project: 
The main kind of trigger [to join the mentorship project] was that when I was in my third year of nursing school, I was in a general internal medicine rotation, and we had a palliative patient on the unit who was HIV-positive and had progressed to AIDS disease, and all of the nurses on the unit just had kind of really bad stereotyping and really bad treatment towards this patient; nobody really wanted to go in and provide the care. I did go in with nurses a few times to provide the care, and I just didn't feel very comfortable about the nursing care that we were providing for the patient... And nurses' attitudes towards people who have this chronic disease. Because I think people who have other chronic diseases, lifestyle diseases, we don't harbour as much resentment, or you wouldn't have a malattitude towards somebody who has cancer, but we hold negative feelings towards people who have AIDS, I think. (Urban mentee)

Several of the nurse mentees wanted to not only learn more about HIV and AIDS for their own professional growth, but were also interested in using that knowledge to change practice:

There's so much more that I need to know, and I just feel that it would create better understanding in my practice, and hopefully in the practice at that clinic or anywhere else. It would be nice to see-my idea of research is eventually to move it past just this part, and to move it into practice; so to actually bring it to a place where change occurs... (Urban mentee)

I'm going to have to support nurses in gaining these skills to have these conversations and present these options to their patients, and I want to be able to support them effectively to do that. So that was my main interest in coming here and participating, and also because I think there are a lot of opportunities in health care to sort of break out of these silos and look at people as whole human...so I thought this could be an opportunity for me to be mentored by some experienced HIV nurses, and then I could, in turn, help empower my staff to move this project forward. (Urban mentee)

One of the public health nurses was keen to begin to use her new knowledge during her home visits.

I think so far, I've missed that [HIV education] - I cover sometimes the STIs, but not specifically HIV, also because my knowledge is minimal, and I think having — even after last weekend, I thought, "I'm going to start using that now on my visits," because it is still out there, and we kind of forget about it. (Urban mentee)

A few of the nurse mentees were interested in a nursing career that included specialized HIV care:

I'm always looking to expand my personal and professional education, and working with people living with HIV as well as providing HIV and AIDS care has been something that I've been interested in and would like to move into and specialize in as my career unfolds. (Urban mentee)

I want to know a lot more than I do now, so everything: transmission, mechanism, even the CD4 counts, I didn't know enough about that. I also want to know how to apply my knowledge practically, and I would like to become an HIV nurse at some point in time, so I really want to build a good foundation. (Rural mentee)

In one of the rural sites, nurses worked with many First Nations clients and communities. They were concerned about the high rates of HIV in their communities and saw the mentorship project as one strategy to increase their own knowledge about HIV, "provide direction and lobbying for change for our clients..." (Rural mentee) and increase awareness of HIV and AIDS in these communities.

That's the big thing, we're just opening our eyes, and there's a lot of work that needs to be involved, and our community has to be aware of it. By being in the research program, prevention, is bringing out that vast 
knowledge of how it's contracted and how to prevent it and how to live a healthy lifestyle, and getting all the tools and teaching, bringing it to our community. (Rural mentee)

I'm speaking for my community, because of the high rates we're seeing. We want to stop the progression right now, so we want to see them-prevent it from happening, but also, we want to service the ones that are living with HIV. So we want to-I wanted to make it more holistic where it's not-I want to see the change, make it where it's not going to be top-bottom approach where it's going to be from ground up, and based on our culture, where if it’s going to be holistic, we also have to integrate a traditional piece as well. (Rural mentee)

The nurse mentors also shared various reasons for participating:

So the reason I did the mentorship, truly, was to continue to foster the mentorship that I have been doing, but to actually be able to open it up to even more people that I may not have been able to get to, for example, the ICU nurses that desperately need this... (Rural mentor)

So this project came to light, and I'm always interested in research and promoting research for my nurses, so I thought it would be a good opportunity for me to further develop my mentorship skills, 'cause as a nurse, you always need to grow and develop and explore more, so I thought this was a good opportunity. I'm by no means an expert around HIV care, but I have a good solid base around it...I hope to grow professionally. [laughs] As a mentor, I try to set a good example and to-mentorship to me means coaching, and as I say, setting an example of what is professional for me, a professional nurse. So I just hope this project will help me grow in that field. (Urban mentor)

\subsection{Nurses' education about HIV}

\subsubsection{Basic undergraduate education}

When asked about HIV education during their undergraduate nursing education, most participants had limited theoretical and practical opportunities to learn about HIV in general, and HIV nursing care in particular. Respondents from several sites commented on their preparation in HIV and AIDS during their basic education:

Nothing and I've never had any exposure. I graduated from university in [Eastern Province \#2], and we never [learned about HIV or AIDS]...As a student, it's almost like we're sheltered from that, that if someone was on the unit who would have been HIV-positive, us students probably wouldn't have had the opportunity anyway. I find students get the easy, basic patients, and you don't really get involved with anyone who's more difficult...But never as a student do I ever remember coming in contact with anyone, or even knowing of anything we could take part of." (Urban mentee)

I don't think it's one of the questions around nursing practice and knowledge; I mean it's [HIV and AIDS] not something you learn in nursing. (Rural mentee)

If you go back 15 years ago, the idea of HIV was nothing but fear, end of story. Then as time goes by and maybe you hear a little bit more one way or another —and certainly my studies, my nursing studies, it was introduced in the curriculum, we brushed on it and so forth—and I'm finding the more I learn, the less scary it is. (Rural mentee)

Interestingly several of the nurse mentees who had learning opportunities related to HIV and AIDS during their basic education had organized this on their own initiative: 
In my nursing student experience, I attended a lot of conferences, actually, and there was some workshops and some seminars and plenary sessions that I attended that were specifically about HIV and AIDS. (Urban mentee)

It was my own initiative to decide to do papers and stuff on those type of topics because I had a personal interest in it, and 'cause I knew that's kind of where I wanted to take my nursing. I did have a placement at [Clinic G], so within the Positive Outlook program, which is a community HIV management program; for my community placement at [Western University E], I was there. For my preceptorship, I worked at the Immune Deficiency Clinic, which is a clinic where all the clients are HIV-positive... I was lucky to have those opportunities available, and I worked with the faculty to really push to have made those opportunities available to me...” (Urban mentee)

\subsubsection{Continuing professional education}

Similarly, following their basic education, there was often limited opportunity for nurses' ongoing professional education related to HIV nursing care. Two nurses from corrections stated that when they started in corrections there were very few opportunities to learn about HIV and AIDS. One nurse mentee working in corrections said that she learned about HIV "at work and I learn from the women.” (Rural mentee). She had limited opportunities for continuing education and shared that in corrections, nurses "...kind of work in isolation. When I first started, we worked by ourselves, so unless you kept yourself current...[it was hard to keep up]". One of the nurse mentees from an urban site commented on the lack of continuing education opportunities:

Certainly in-services and support for education was extremely hard to come by in [Eastern Province \#1], so my early nursing career, I’d say no.” (Urban mentee)

Similarly, when asked if there were opportunities for continuing professional development in her community, a rural participant replied "No. We lack that very much here" (Rural mentee). One of the mentees believed that there was less emphasis on, including fewer questions about, HIV in her past several years working as a nurse:

I think years ago when I first started, I think we actually talked a little bit more about it than we have in the last even 4 or 5 years. So not consciously, but for some reason, people asked more, there was a little bit more fear about it, and even the girls, I would sometimes hear them ask me about that when we were talking about safe sex practices. But to be honest, in the last few years, I don't think I've had any young woman ask me about HIV or their risk; we've just kind of lumped it into sexual transmitted infections, and a little bit of a discussion, and of course, some of the testing they do during pregnancy, and one of them is the HIV. But not in great depth. (Urban mentee)

One of the rural participants commented that the mentorship research project was only the second opportunity she had had to learn more about HIV care:

Prior to this, [Nurse mentor] and [social worker from ASO] did offer a lunch session at the hospital...so I took advantage of that. But prior to that—and even when I worked elsewhere in northeastern [Eastern province \#3] I don't—it doesn't seem to be something that comes up a lot. This is probably the second time, the first time being their lunch-and-learn back in October or November. (Rural mentee)

One of the mentees recalled having three patients who were HIV positive but she had not had any preparation to care for them. She believed that "It may be smart even for them to cover HIV in hospital orientation "(Urban mentee). Similarly one of the nurse mentees spoke of the urgent need for continuing education for nurses working in First Nations communities:

Because when you work in the communities, in First Nations communities—and a lot of band-employed nurses, their opportunities are not as, you know - they're not given that opportunity to bring their knowledge base up. 
These band-aid solutions, like having workshops once a year, twice a year, is not enough; we need to build ongoing...mentoring opportunities, continue ed, or else through web-base or whatever-you know, provide that opportunity for the nurses to bring up their skills. Because I know there are nurses out there who refuse to give care [to HIV positive patients]. (Rural mentee)

This participant went on to urge communities and elders to be involved with continuing education plans:

Like, they [Health Canada] really need to take direction from the community and their training needs and their competency needs where they are, and they really need to start, I guess, to build capacity in this community and within our own staff and also within the community, using our elders to be part of the solution. And I guess overall, we're always looking for answers from outside, when really, we have the answers within our community...We take guidance from our elders and our knowledge keepers as to how we should maintain the health and well-being of the community, and not always look at the illness, but look at wellness. (Rural mentee)

In addition to the opportunity for formal professional development, some of the nurse mentees spoke about their learning through real life experiences and self-directed learning:

I've dealt with possibly maybe three or four HIV clients now, and at different stages of their disease. I guess it's been quite a learning experience, but the formal education that I received through workshops, through school has helped me, but it’s the more real-life experiences that have taught me the most from the clients and their families. (Rural mentee)

At that time, it was basically self-learning — well, definitely learning from co-workers who have been doing it a long time, so obviously, reading standards, policies and procedures at the health unit there. But it wasn't until...post-grad, nothing, really, unless it was self-directed. (Rural mentee)

There were some nurse mentors and mentees, on the other hand, who spoke very positively about their opportunities for continuing HIV professional education:

In the position that I am now, it's encouraged, and any opportunity that we find, it's always supported, and our training is-we get to go on a significant amount of training in this present position. I just think with our provincial strategy now, there is a lot more opportunities for training and workshops. (Rural mentor)

We get all kinds of education opportunities that people in other health authorities would never get. So we're very lucky; I think we're in a bit of a bubble. (Urban mentor)

But it wasn't until I came here to [Public Health Centre C] where I'm really—I've been fortunate enough to not only go back to the testing part, but actually having to give HIV clients positive diagnoses. I've been to the HIV conference in [Eastern City \#3] by the AIDS Bureau, so I have some information there. I've been to a few in-services or educational sessions with [Nurse mentor1] - and she's been a good mentor that way. But I've also had the opportunity to, where I'm working now, institute point-of-care HIV testing, so rapid HIV testing, so I had to do a lot of research into that. (Rural mentee)

\subsection{Nurses' knowledge and experience with HIV}

\subsubsection{Nurses lack of knowledge}

A number of the nurse mentees spoke about the gaps in their knowledge about HIV and AIDS and about their lack of understanding about where HIV specialized care was provided. One of nurses at an urban site shared: 
I really didn't even know about the HIV clinics at the [Hospital B] and the [Hospital C]; I had no idea. I didn't know some of those physicians and how passionate their work is around this, and some of the expertise, I had no idea...I really don't know, even, do they have a separate unit? Is it integrated, or is there somewhere where clients go?” I really didn’t know. (Urban mentee)

One of the rural nurse mentees had cared for HIV positive patients; however, she did not have the in-depth knowledge required to provide ongoing care:

I took care of clients who were HIV-positive, but I don't - again, in terms of their medications, it was just whatever they were in for. I'd only see them for a short period of time, so it wasn't anything I could take care of them over a period of time, so I didn't really get a lot of information on how to care for those individuals. (Rural mentee)

A rural nurse mentee who worked with hepatitis C patients felt that she had been uninformed about the prevalence of HIV in the community:

I think I was naïve to the situation; I think I was naïve. One, like I said, I work as a Hepatitis C treatment nurse, and I couldn't believe how many people had Hepatitis C. So when these people started coming to me and they were co-infected, I didn't - I was floored by it. I didn't recognize the problem in our community. I knew it was out there, of course, but I don't actively treat HIV; like, I actively treat Hepatitis C, so we do referrals out for the co-infected. (Rural mentee)

A conversation with one of the nurse mentors about a friend made a rural nurse mentee realize what she didn't know about HIV and AIDS:

The moment that I connected with [nurse mentor] on his behalf, I realized just by hearing her talk, nurse to nurse, I don't know anything about this disease...It just brought forth to me because of my personal connection what I didn’t know. (Rural mentee)

\subsubsection{Nurses experience in HIV care}

Many of the mentees had very vivid memories of their experiences caring for PHAs or dying from AIDS:

I know exactly who they are. I don’t remember the exact doses of medications, but I know exactly who they are... (Urban mentee)

I just remember it was a man, just a young man, and he was dying, and it was just systemic, and it was very powerful, just the way he had to breathe, lifting up his knees to take breaths. Yes, that's very vivid. So that was my first experience with people living with HIV and AIDS...That was probably 1990 [pause] about there... I'm just trying to think-I haven't had much contact. (Urban mentee)

Some of the nurse mentees spoke about the powerful impact that one patient had on their understanding of HIV and their attitudes toward PHAs. One participant worked in public health in a small city and recalled only one patient that she had cared for who was HIV positive. The physician had tried to refer the patient to a larger centre for maternity care, but the woman refused:

We recently had a woman who was pregnant with HIV who came to our community, and was immediately referred to [Western City \#3], and she actually refused. She became the first patient that they've identified to be HIV-positive who was going to deliver in [Western City \#4]. She was an advocate for herself and said, "No, I'm healthy, I'm fine, there's no reason why I can't deliver here.” So what we did is we developed a team to deal with 
her, so I was selected to make contact, establish a relationship with her, follow her through the end of her pregnancy, attend the pharmacy teaching with her, 'cause baby needs meds. So I established that rapport with her... (Urban mentee)

When asked if she had experience caring for PHAs a rural nurse mentee replied "No, I haven't actually dealt with a whole lot of people with HIV. And in fact, I didn't realize there were that many cases here”. A nurse mentee in a smaller rural setting found her attitude to PHAs changing after she cared for a man dying from AIDS:

So I got to kind of see the end of a life of an AIDS client...But this man was so sweet. I had known him for years before, and I hadn't known he had AIDS, because he was a teacher. He was around kids all the time and he was such a sweet man. He just kind of changed my view, my view on taking care of an HIV and AIDS client... (Rural mentee)

Both nurse mentors and mentees spoke of the stigma and discrimination that they had encountered during the care of HIV positive patients. One nurse mentor spoke about the challenges associated with providing consultations to other in-patient units in her hospital. She stated "we deal with a lot of discrimination from other units". When asked why, she commented "I think for the most part, people are hesitant to get involved in something that they know they don't understand very well." (Urban mentor) The same nurse went on to describe some of the challenges she'd experienced with non-HIV specialized colleagues in her hospital:

We've overheard some of the employees say to these, like, "Let me disinfect this room one more time. I think an HIV person was in here.” We get shuffled around. It feels like we kind of just get stripped of every right that we have; like, they don't want us in their clinic, they don't want to share the space with us, and I don't know if it's 'cause we're the HIV program, or because we're any program that's invading their space.” (Urban mentor)

A rural nurse mentee commented on the stigma she had observed in her practice:

Just talking to those two ladies [PHA participants], it just blows my mind how awful they've been treated ...the stigma involved is incredible. So I would like to be able to help change the stigma that's involved with HIV. And for some reason, HIV and addiction goes together, so I would like to be able to be able to change all that. (Rural mentee)

One of the nurse mentors shared her thoughts on why she believed that HIV should be treated differently than other infectious diseases:

What does make HIV special, then? I think it is sort of the stigmatization and all those other things that sociologically, spiritually, bio—you know, psychosocially, spiritually—that affect the person that has HIV and the community within it that makes it different. (Urban mentor)

Two of the nurse mentees also spoke in strong support about the benefits of continuing to provide HIV specific nursing education:

We know there's gaps with nursing, the knowledge base, it's big time. I believe that all nurses should have that knowledge base of how to care for HIV and be aware of what are the treatments and how to look after them. Right now, it's not there. (Rural mentee)

A rural nurse mentee commented "I believe that it [HIV] is a specialty because it's just so distinct in terms of...you know there's a lot to know.” (Rural mentee). 


\section{Discussion}

Currently, there are approximately 71,300 PHAs in Canada ${ }^{[31]}$. As a result of this reality, PHAs will continue to interact with health care system at all levels, as they seek treatment for HIV, concurrent chronic illnesses and aging-related diseases. Therefore, a highly qualified nursing workforce is still essential to provide HIV care ${ }^{[10]}$. What we learned from the mentorship project is that although many nurses were interested in improving their HIV care of others, few opportunities existed for them to do so. In some of the organizations that we approached, HIV was not perceived as a priority health concern and, therefore, decision makers were unwilling to give the administrative approval required to recruit nurses at their site. Furthermore, some nurses were denied permission to attend mentorship workshops forcing them to take their annual leave in order to participate. We were concerned that, at times, nurses did not have personal agency to decide what educational opportunities were important to them.

HIV education has the potential to contribute to HIV prevention by increasing knowledge and shifting attitudes, thereby reducing HIV risk and vulnerability ${ }^{[32]}$ and is key to addressing HIV stigma in health care settings ${ }^{[33]}$. Despite the potential positive impact of education on the global HIV epidemic, Aggleton and colleagues ${ }^{[32]}$ argue that there has been limited documentation of different approaches to HIV education and research to evaluate the impact of the different approaches. As we implemented this study, we began to appreciate that HIV nursing education and expertise were significantly different among participants and across clinical sites. This difference was visible in basic education, services offered for HIV and AIDS care, the collaborative and inter-professional nature of care, and opportunities for continuing education in HIV and AIDS nursing care.

Some participants commented on the need to treat HIV and AIDS differently than other infectious diseases. This approach emerged in the first decade of the epidemic and is referred to as "AIDS exceptionalism" ${ }^{34]}$. Over the ensuing decades several tensions have been identified related to using an AIDS exceptionalism approach for HIV care, treatment and support. For example this approach evokes tension between the protection of individual human rights versus best public health practice ${ }^{[14,35,36]}$. AIDS exceptionalism evokes a parallel tension for nurse educators. Should HIV and AIDS be taught using a disease specific approach or integrated into modules that include other chronic diseases, blood borne pathogens or infectious diseases? In a Journal of the Association of Nurses in AIDS Care editorial, Sowell ${ }^{[37]}$ argues that it is time for nurses in AIDS care to expand their perspective to embrace the global understanding of HIV as an illness that is influenced by the environmental factors, cultural beliefs, and social determinants that are also common to other illnesses. He cautions however that in expanding their perspective, nurses must be careful to balance their primary focus on HIV and AIDS, with an expanded understanding of illnesses that are influenced by the social determinants of health.

In the current study we were unable to obtain administrative and ethical approval at two sites; this challenge appeared to reflect the value afforded our research study and the overall political environment in the respective institutions. The care, treatment and support of PHAs has always been influenced by the political environment in which care takes place. For example, Bradley-Springer ${ }^{[38]}$ provides a compelling critique of the shortcomings of the President's Emergency Plan for AIDS Relief (PEPFAR) program because it was based on the political ideology of the United States government of the time, rather than scientific evidence. Similarly the education of Canadian nurses to provide HIV care is influenced by the values of the institutions providing basic education to nurses, the philosophy of the organizations where nurses' work, and the political beliefs and policies of governments related to the provision of health services for society's often most marginalized individuals and communities.

The inadequacies in nursing education to prepare nurses to provide HIV nursing care reported in the current project were recently highlighted by CANAC ${ }^{[21]}$. As educators we were particularly struck by the continuous absence of HIV and AIDS in nursing curriculum, a finding that was consistent across all sites. While we did not study curriculum at individual Canadian universities or schools of nursing, our nurse participants graduated from diverse schools and at different times and all of them reported a similar absence of curriculum. While HIV is increasingly being considered a chronic condition and one that should be integrated with the care of other infectious diseases (e.g., Hepatitis C, Sexually Transmitted 
Infections, and Blood Borne Pathogens), we wonder if an integrated approach will further silence the preparation of new graduates for HIV care, or decrease opportunities for practicing nurses to learn about HIV care, treatment and prevention. We applaud CANAC ${ }^{[21]}$ for recommending basic competencies necessary for new graduates. Given our current findings, it is extremely important for nurse educators across all institutions, both universities and care practice sites, to take these recommendations seriously.

Mentorship education is an effective strategy to not only address a critical void in knowledge, but also to promote a fundamental shift in attitudes, thereby mitigating some of the negative consequences of the AIDS epidemic. The development of interventions to establish an environment of care that mitigates AIDS stigma is a complex and multi-level process. The experiences of stigma at the individual level intersects and overlaps with, the broader context of health care delivery including health care professionals, the health care system, and society ${ }^{[2]}$. With the recent call by the World Health Organization ${ }^{[39]}$ to place nurses in key positions to provide HIV care, treatment and prevention, it is imperative to prepare nurses at both the undergraduate and graduate level, as well as those in practice, to fulfill these new positions. While medical interventions have often been heralded as the cure for HIV, it is the engagement of nursing in meaningful, informed and ethical care that makes not only the implementation of these interventions possible, but also creates the possibility to address structural and political inequities that continue to deeply shape the current and future possibilities of HIV nursing care in Canada and globally.

\section{Acknowledgments}

We are grateful for the dedication and shared insights of all our participants and co-investigators. We thank all our partner organizations including the AIDS Service Organizations across Canada for their unending support of this project and their continuous commitment to advance care. We also extend our thank you to the community advisory committee for providing ongoing guidance to the project team. The Canadian Institutes for Health Research (CIHR) provided funding for this project.

\section{References}

[1] Grossman CI, Stangl AL. Global action to reduce HIV stigma and discrimination. Journal of the International AIDS Society. 2013; 16(Suppl 2): 18881. http://dx.doi.org/10.7448/IAS.16.3.18881

[2] Mill J, Edwards N, Jackson R, Maclean L, Chaw-Kant J. Stigmatization as a Social Control Mechanism for Persons Living with HIV and AIDS. Qualitative Health Research. 2010; 20(11): 1469-1483. PMid:20663937 http://dx.doi.org/10.1177/1049732310375436

[3] Ekstrand M, Ramakrishna J, Bharat S, Heylen E. Prevalence and drivers of HIV stigma among health providers in urban India: Implications for interventions. Journal of the International AIDS Society. 2013; 16(Suppl 2): 18717. http://dx.doi.org/10.7448/IAS.16.3.18717

[4] Mill J, Edwards N, Jackson R, Austin W, Maclean L, Reintjes F. Accessing health services while living with HIV: Intersections of stigma. Canadian Journal of Nursing Research. 2009; 41(3): 168-185. PMid:19831060

[5] Bradley-Springer L. The 25th year. Journal of the Association of Nurses in AIDS Care. 2012; 23(1): 4. http://dx.doi.org/10.1016/j.jana.2011.12.003

[6] Association of Nurses in AIDS Care. ANAC’s Mission Statement. 2013. Available from: http://www.nursesinaidscare.org/i4a/pages/index.cfm?pageid=3284 (June 17th, 2013 date last accessed)

[7] Association of Nurses in AIDS Care. ANAC’s Core Curriculum for HIV/AIDS Nursing. 2010. (3rd Ed.). B. Swanson (ed.) Jones \& Bartlett Learning: Burlington, VA. Available from: http://www.nursesinaidscare.org/i4a/pages/Index.cfm?pageID=3681 (June 17th, 2013 date last accessed)

[8] Canadian Association for Nurses in AIDS Care. History of the Canadian Association for Nurses in AIDS Care. 2013. Available from: http://www.canac.org/English/ (April 9th, 2013 date last accessed)

[9] International Council of Nurses. ICN Networks, HIV/AIDS Network: Network History. 2013. Available from: http://www.icn.ch/networks/hiv-aids-network/ (September 5th, 2013 date last accessed)

[10] Relf MV, Mekwa J, Chasokela C, Nhlengethwa W, Letsie E, Mtengezo J, et al. Essential nursing competencies related to HIV and AIDS. Journal of the Association of Nurses in AIDS Care. 2011; 22(IS), e5-e40. http://dx.doi.org/10.1016/j.jana.2010.07.007 
[11] Bradley-Springer L. Education is a special issue. Journal of the Association of Nurses in AIDS Care. 1996; 7(1): 3-4. http://dx.doi.org/10.1016/S1055-3290(96)80001-X

[12] Corless IB, Nokes KM. Professional nursing education's response to the HIV/AIDS epidemic. Journal of the Association of Nurses in AIDS Care. 1996; 7(1): 15-22. http://dx.doi.org/10.1016/S1055-3290(96)80003-3

[13] Gallagher DM. HIV education: A challenge to adult learning theory and practice. Journal of the Association of Nurses in AIDS Care. 1996; 7(1): 5-14. http://dx.doi.org/10.1016/S1055-3290(96)80002-1

[14] Gitman M. Exceptionalism and inclusion in the modern HIV era. Virtual Mentor: American Medical Association Journal of Ethics. 2009; 11(12): 930-932. Available from: http://virtualmentor.ama-assn.org/2009/12/fred1-0912.html

[15] Association of Nurses in AIDS Care. Position Statement: HIV Risk Assessment and Risk Reduction Education. Journal of the Association of Nurses in AIDS Care. 1992; 24(2): 183-184. http://www.nursesinaidscare.org/i4a/pages/Index.cfm?pageID=3958

[16] Canadian Association for Nurses in AIDS Care. A Comprehensive Guide for the Care of Persons with HIV Disease: Module 3 Nursing Care. 1996. Toronto, Ontario.

[17] Paquin M, Lambert A. The collaborative project: An effective Canadian partnership in HIV/AIDS nursing care. Journal of the Association of Nurses in AIDS Care. 2000; 11(4): 57-64. http://dx.doi.org/10.1016/S1055-3290(06)60396-8

[18] Charles G, Bainbridge L, Gilbert J. The University of British Columbia model of interprofessional education. Journal of Interprofessional Care. 2010; 24(1): 9-18. http://dx.doi.org/10.3109/13561820903294549

[19] Phillips JC, De Palma C, Kerston RP, Sakakibara T, Booth W, Petty M, et al. Interprofessional Health and Human Service - HIV Prevention and Care: Brief Report Preliminary Course Impact Evaluation. 2012. College of Health Disciplines, University of British Columbia. Available from: http://www.chd.ubc.ca/files/file/ihhs/BriefReportIHHS402ImpactEvaluation2012.pdf

[20] McCall J, Bath M, Phillips, JC, Kumar M, Connolly K, Spencer D, et al. Best Practice Guidelines: Caring For Clients who are at Risk For and Living with HIV/AIDS. Canadian Association of Nurses in AIDS Care 2012. Available from: http://www.catie.ca/sites/default/files/Best\%20Practice\%20Guidelines\%20Final\%20April\%202012.pdf (January 17th, 2014 date last accessed)

[21] Canadian Association for Nurses in AIDS Care. Core Competencies for HIV/AIDS Nursing Education at the Undergraduate Level: Position Paper. 2013. Author: Ottawa. Available from: http://www.canac.org/Resources/CANAC_core_comp_e.pdf (January 17th, 2014 date last accessed)

[22] Andrews M, Wallis M. Mentorship in nursing: A literature review. Journal of Advanced Nursing. 1999 ; $1(29)$ : $201-207$. http://dx.doi.org/10.1046/j.1365-2648.1999.00884.x

[23] Callaghan D, Watts WE, McCullough DL, Moreau JT, Little MA, Gamroth LM, et al. The experience of two practice education models: Collaborative learning unit and preceptorship. Nurse Education in Practice. 2009; 9: 244-252. http://dx.doi.org/10.1016/j.nepr.2008.08.010

[24] Copley J, Nelson A. Practice educator perspectives in multiple mentoring in diverse clinical settings. British Journal of Occupational Therapy. 2012; 75(10): 456-462. http://dx.doi.org/10.4276/030802212X13496921049662

[25] Ambrose L. Multiple mentoring: Discover alternatives to a one-on-one learning relationship. Health Care Executives. 2003; 18(4): 58-59.

[26] Grindel CG, Patsdaughter CA. Coming full circle: Mentorship in HIV/AIDS Care. Journal of the Association of Nurses in AIDS Care. 2000; 11(6): 54-63. http://dx.doi.org/10.1016/S1055-3290(06)60355-5

[27] Solomon P, O’Brien K, Hard J, Worthington C, Zack E. An HIV mentorship programme for rehabilitation professionals: Lessons learning from a pilot initiative. International Journal of Therapy and Rehabilitation. 2011. 18(5): 280-289. Available from: http://www.ijtr.co.uk/cgi-bin/go.pl/library/abstract.html?uid=83676

[28] Mezirow J. Transformative learning: Theory to practice. New Directions for Adult and Continuing Education. 2007; 74: 5-12. San Francisco: Jossey-Bass.

[29] NVivo qualitative data analysis software; QSR International Pty Ltd. Version 9, 2010.

[30] Morse JM. "Emerging from the data": The cognitive processes of analysis in qualitative inquiry. In J. M. Morse (Ed.), Critical issues in qualitative research methods. 1994. 23-43. Thousand Oaks, CA: Sage.

[31] Public Health Agency of Canada. Summary: Estimates of HIV Prevalence and incidence in Canada. 2011. Available from: http://www.phac-aspc.gc.ca/aids-sida/publication/survreport/assets/pdf/estimat2011-eng.pdf. (December 9th 2013 date last accessed)

[32] Aggleton P, Yankah E, Crewe M. Education and HIV/AIDS - 30 years on. AIDS Education and Prevention. 2011; $23(6)$ : $495-507$. http://dx.doi.org/10.1521/aeap.2011.23.6.495

[33] Surlis S, Hyde A. HIV-positive patients' experiences of stigma during hospitalization. Journal of the Association of Nurses in AIDS Care. 2001; 12(6): 68-77. http://dx.doi.org/10.1016/S1055-3290(06)60185-4 
[34] Bayer R. Public health policy and the AIDS epidemic: An end to HIV Exceptionalism? New England Journal of Medicine.1991; 324(21): 1500-1504. http://dx.doi.org/10.1056/NEJM199105233242111

[35] Bayer R, Edington C. HIV testing, human right and global AIDS policy: Exceptionalism and its discontents. Journal of Health Politics, Policy and Law. 2009; 34(3): 301-323. http://dx.doi.org/10.1215/03616878-2009-002

[36] Fisher WA, Kohut T, Fisher JD. AIDS Exceptionalism: On the social psychology of HIV Prevention Research. Social Issues and Policy Review. 2009; 3(1): 45-77. http://dx.doi.org/10.1111/j.1751-2409.2009.01010.x

[37] Sowell RL. Expanding our perspective. Journal of the Association of Nurses in AIDS Care. 2007; 18(1): 1-2. http://dx.doi.org/10.1016/j.jana.2006.11.021

[38] Bradley-Springer L. Political ideology, HIV infection, and PEPFAR. Journal of the Association of Nurses in AIDS Care. 2010; 21(5): 377-379. http://dx.doi.org/10.1016/j.jana.2010.07.004

[39] World Health Organization. Consolidated guidelines on the use of antiretroviral drugs for treating and preventing HIV infection. Recommendations for a public health approach. 2013. Geneva: Author. Available from:

http://apps.who.int/iris/bitstream/10665/85321/1/9789241505727_eng.pdf (9th December 2013 date last accessed) 